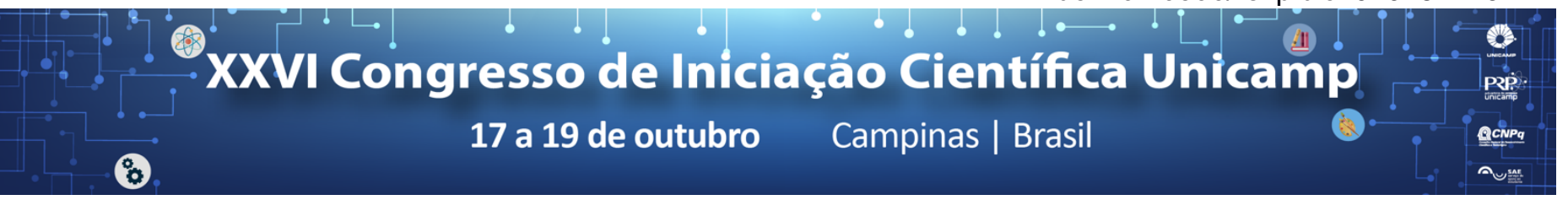

\title{
Algoritmos de Sequenciamento de Tarefas e uma Aplicação ao Problema de Sequenciamento da Produção Agrícola
}

\section{Rodrigo G. R. Mendonça*, Priscila B. Rampazzo.}

\section{Resumo}

Esse trabalho consistiu em modelar o Problema de Produção Agrícola como um Problema de Sequenciamento de Tarefas e obter soluções para esta aplicação através de uma Metaheurística, pois o problema é classificado como NP. difícil. A abordagem proposta foi um Algoritmo Genético (da classe das Metaheurísticas Evolutivas), desenvolvido levando em consideração o tempo de plantio de cada planta, sua lucratividade e seu período de cultivo, fatores característicos desse tipo de problema. Ao se analisar diversas instâncias de teste, pode-se perceber que o algoritmo proposto conseguiu encontrar soluções factíveis e de qualidade para o problema, em pequeno tempo computacional.

\section{Palavras-chave:}

Sequenciamento de Tarefas, Algoritmos, Produção Agrícola, Metaheurística.

\section{Introdução}

O Problema de Sequenciamento da Produção Agrícola, também conhecido por Problema de Rotação de Culturas (Crop Rotation Problem, ou CRP) (Aliano Filho et. al., 2014; Santos et. al., 2008) consiste em encontrar a melhor maneira de realizar o plantio de espécies, obedecendo as restrições impostas por cada tipo de cultura, maximizando os lucro obtido. Utilizou-se como parâmetros: a lucratividade de cada espécie, que foi considerada constante durante todo o ano; o período de cultivo de cada uma; o tempo que cada planta necessita para crescer, desde o plantio até a colheita, que deve estar totalmente contido no seu período de cultivo; e a necessidade de serem plantadas espécies diferentes em sequência no mesmo terreno. Nesse trabalho não foram utilizadas restrições de demanda, de espécies iguais em terrenos adjacentes, de lucratividade com variação ao longo do ano, ou de família de plantas; informações que serão analisadas em um trabalho futuro. Algoritmos Genéticos (AG) têm sido amplamente aplicados na resolução deste tipo de problema, por explorarem o espaço de busca de forma eficiente.

\section{Resultados e Discussão}

Primeiramente, o algoritmo proposto se utiliza dos tempos de produção e período de plantio fornecidos, para criar uma solução inicial factível (indivíduo), selecionando aleatoriamente a alocação das diversas espécies. Esse primeiro passo é importante pois agiliza o método, eliminando a necessidade de manipular soluções infactíveis. Em seguida, foi implementada a avaliação do conjunto de soluções geradas (população). Este conjunto participa da criação de novos indivíduos, através de recombinação (crossover) e mutação. Os melhores indivíduos selecionados serão parte da geração seguinte. Os cinco melhores são selecionados diretamente e os demais passam por uma seleção de roleta, na qual cada solução possui uma probabilidade de ser selecionada para a próxima geração baseada em sua função-objetivo, ou seja, as soluções que possibilitam maiores lucros têm mais chances de serem selecionadas. A Tabela 1, apresenta uma instância com 5 espécies, tempo de produção em períodos e a lucratividade em unidades monetárias. Considerando 12 períodos e 5 terrenos, com 100 gerações e uma população de 100 indivíduos, uma solução (Figura 1, Gráfico de Gantt), foi obtida pelo algoritmo em 0.422359 segundos, com lucro 135. Não foi possível comprovar se a solução é a ótima, porém, na primeira geração a população apresentou lucro médio 121. Com metade das gerações, a melhor solução encontrada obteve lucro 131, o que demonstra que os operadores do algoritmo têm obtido resultados satisfatórios e o AG tem demonstrado ser uma abordagem promissora.

Figura 1. Solução do AG .

\begin{tabular}{lllllllllllll|}
1 & 2 & 3 & 4 & 5 & 6 & 7 & 8 & 9 & 10 & 11 & 12 \\
2 & 1 & 1 & 5 & 5 & 5 & 5 & 5 & 3 & 3 & 2 & 2 & 2 \\
3 & 1 & 1 & 5 & 5 & 5 & 5 & 5 & 3 & 3 & 2 & 2 & 2 \\
4 & 1 & 5 & 5 & 5 & 5 & 5 & 3 & 3 & 2 & 2 & 2 \\
5 & 1 & 1 & 5 & 5 & 5 & 5 & 5 & 3 & 3 & 2 & 2 & 2 \\
1 & 1 & 5 & 5 & 5 & 5 & 5 & 3 & 3 & 2 & 2 & 2 \\
\hline
\end{tabular}

Tabela 1. Dados das espécies utilizadas no método.

\begin{tabular}{cccc} 
Espécie & Tempo de Produção Lucratividade & Período de plantio \\
\hline 1 & 2 & 2 & {$[1,6]$} \\
\hline 2 & 3 & 6 & {$[7,12]$} \\
\hdashline 3 & 2 & 2 & {$[5,12]$} \\
\hdashline 4 & 4 & 10 & {$[4,10]$} \\
\hdashline 5 & 5 & 15 & {$[3,12]$}
\end{tabular}

\section{Conclusões}

$\mathrm{Na}$ primeira etapa do projeto foram analisados dois modelos de Sequenciamento de Tarefas em máquinas paralelas. Os resultados foram divulgados um artigo publicado no ERPO 2018 (Passos et. al., 2018).

Aliano Filho, A.; Florentino, H. de O.; Pato, M. V. Metaheuristics for a crop rotation problem. Int. J. Metaheuristics, v. 3, n. 3, 2014.

Santos, L. M. R. dos; Michelon, P; Arenales, M. N.; Santos, R. H. S. Crop rotation scheduling with adjacency constraints. Springer Science+Business Media, LLC, 2008.

Passos, G.; Pennone, M. D.; Mendonça, R. G. R.; Shie, W. H.; Rampazzo, P. C. B. Algoritmos para o Sequenciamento de Tarefas em Máquinas Paralelas, Anais do III Encontro Regional de Pesquisa Operacional - ERPO, 2018. url: https://drive.google.com/file/d/1QJmJ7bbeW-

yypLjXJ5aYd9EytudNzzcK/view 